\title{
Análise da cadeia produtiva do capim limão: estudo de caso
}

GOMES, E. C. ${ }^{*}$; NEGRELLE, R.R.B ${ }^{2}$

1Universidade Federal do Paraná, Departamento de Saúde Comunitária - R. Pe. Camargo, 280 - Curitiba, PR 80060-240 - elianegomes@ufpr.br (autor para contato); 2 Universidade Federal do Paraná, Departamento de Botânica, Caixa Postal 19031, Curitiba, PR, 81531-990; negrelle@ufpr.br

\begin{abstract}
RESUMO: Apresentam-se 26 propostas e recomendações aos agentes econômicos da cadeia produtiva do capim-limão, considerando resultados de diferentes estudos sobre o cultivo e a comercialização desta espécie no Estado do Paraná, Brasil. As propostas e recomendações estão categorizadas de acordo aos distintos problemas identificados, com ênfase no cultivo e processamento, posto que estas atividades foram evidenciadas como as mais problemáticas e limitadoras da oferta de produto adequado ao comércio e ao consumo. Objetivou-se contribuir para a melhor qualificação desta cadeia produtiva gerando benefícios, tanto aos distintos atores nela envolvidos, como também promovendo as bases para garantir a segurança alimentar do consumidor.
\end{abstract}

Palavras-chave: produção, alimento, chá.

\begin{abstract}
Proposals and recommendations for qualification of the production chain of lemon grass (Cymbopogon citratus) (DC.) Stapf (Poaceae). Twenty-six proposals and recommendations for the economic agents of the production chain of lemon grass are presented, considering the results of different studies related to the cultivation and commercialization of this species in the Paraná State, Brazil. These proposals and recommendations were categorized according to the different problems identified, with an emphasis on the cultivation and processing, since these were evidenced as the most problematic and limiting factors in relation to the offer of an adequate product for both trade and consumption. We aim to contribute to the improvement of the production chain of lemon grass, generating benefits to the different players involved in this chain as well as promoting bases to ensure food safety to consumers.
\end{abstract}

Key words: production, food, tea.

\section{INTRODUÇÃO}

Cymbopogon citratus (DC.) Stapf é uma gramínea perene, originária da Índia, mais conhecida como capim-limão na medicina popular, onde é empregada especialmente como chá (Dubey, 1997).

Esta espécie é cultivada em praticamente em todos os países tropicais. No Brasil, a produção desta espécie ocorre destacadamente nas Regiões Sul e Sudeste. No Estado do Paraná, maior produtor de plantas medicinais aromáticas do País, a produção de capim-limão ocupa posição de destaque. A safra -2003/2004 totalizou 1108,6 t, ocupando 39,1 ha distribuídos em 21 municípios produtores. O valor bruto da produção agrícola desta safra totalizou $R \$ 443.456,12$. As safras de 2008 a 2012 tiveram rendimento médio de $970 \pm 247 \mathrm{t}$, ocupando área média $45,54 \pm 12$ ha, distribuída em 30 municípios produtores. $\mathrm{O}$ valor bruto médio da produção agrícola deste período foi de $\mathrm{R} \$ 717647 \pm$ 274560 (SEAB-DERAL, 2014). Estas cifras têm levado este produto a ser classificado como um dos "produtos especiais" mais valorizados no Paraná (PARANÁ, 2005). Esta espécie encontra-se entre as espécies medicinais mais produzidas no Estado, conforme dados fornecidos pela Secretaria de Estado da Agricultura e do Abastecimento - SEAB/ $P R$, referentes às especiarias período 2008-2012.

Nos segmentos industrial e supermercadista na região Sul, especialmente na cidade de Curitiba, o chá de capim-limão, tem sido apontado como um dos principais chás comercializados pelas empresas do ramo (Gomes, 2003).

Além do uso popular bastante reconhecido, para distúrbios nervosos e estomáquicos, o capimlimão tem emprego industrial vasto. As folhas 
desidratadas são utilizadas, principalmente, pela indústria alimentícia para o fabrico de chás. 0 óleo essencial, extraído das folhas, tem emprego tanto na indústria alimentícia, como flavorizante e aromatizante, quanto na indústria farmacêutica na produção de fitoterápicos, inseticidas, cosméticos e perfumaria. Várias propriedades do capim-limão foram comprovadas em experimentos científicos, citando-se entre estas as ações antimicrobiana, analgésica, anticancerígena, repelente a insetos $\mathrm{e}$ inseticida e como fonte de vitamina A (Onawunmi et al., 1984; Onawunmi, 1988; Lorenzetti et al., 1991; Adebayo \& Gbolade, 1994; Balboa \& Lim, 1995; Chalchat et al., 1997; Dubey et al., 1997; Gilbert et al., 1999; Martins \& Melo, 2002).

Considerando a importância econômica da produção, industrialização e comercialização do capim-limão e visando uma ação integrada do setor agrícola envolvido, realizou-se estudo prospectivo da cadeia produtiva desta espécie no estado do Paraná, identificando também fatores e condicionantes de qualidade em cada segmento desta cadeia (Gomes et al., 2004; Gomes \& Negrelle, 2006). Os resultados desta pesquisa integrados aos de outras pesquisas relacionadas ao detalhamento do cultivo (Gomes, 2001; Gomes et al., 2007b); procedimentos de colheita e pós-colheita (Gomes et al., 2007a); acondicionamento e armazenagem de chás (Gomes et al., 2007c); acondicionamento e rotulagem do chá de capim-limão (Gomes et al., 2005); qualidade microbiológica e físico-química de marcas deste chá (Gomes et al., 2008), permitiram identificar um conjunto de inadequações nos vários segmentos da cadeia produtiva do capim-limão no Estado do Paraná. A análise crítica destas inadequações, confrontando-se o que preconiza a literatura pertinente sobre a melhor condição e funcionalidade de cada elo potencialmente envolvido numa cadeia produtiva, possibilitou a geração de propostas e recomendações de melhoria da cadeia do capim-limão aqui apresentadas.

\section{MATERIAL E MÉTODO}

A pesquisa exploratório-descritiva sobre a cadeia produtiva do capim-limão foi baseada em levantamento bibliográfico, documental e pesquisa de campo através da aplicação de formulários com questionamentos fechados, uso de técnica de observação participante e entrevistas semiestruturadas.

A partir de entrevistas, com os técnicos do Departamento de Economia Rural da Secretaria de Agricultura e Abastecimento do Estado do Paraná - SEAB/PR e Empresa Paranaense de Assistência Técnica e Extensão Rural - EMATER/PR, obtiveram- se os dados relativos aos diferentes segmentos e agentes econômicos que atuavam na produção agroindustrial do capim-limão no estado do Paraná. Este universo de entrevistados correspondeu a 34 pessoas, representando 13 Núcleos Regionais da SEAB/PR e englobando 38 municípios paranaenses.

Em outra etapa do trabalho, 22 produtores agrícolas e/ou agroindustriais foram entrevistados com a finalidade de caracterizar o perfil socioeconômico e tecnológico dos mesmos. Adicionalmente, buscou-se identificar junto a estes produtores o fluxo de comercialização deste produto agrícola (Gomes, 2001; 2003).

Posteriormente, procedeu-se entrevistas com representantes de indústrias identificadas como receptoras e processadoras de capim-limão, visando caracterizar também este segmento da cadeia produtiva. Além das indústrias citadas pelos produtores e técnicos da EMATER/PR entrevistados, buscou-se também entrevistar representantes das maiores indústrias curitibanas de produção de fitoterápicos que constavam do Programa Nacional de Inspeção das Indústrias Farmacêuticas e Farmacoquímicas - PNIF, conforme Secretaria de Estado da Saúde do Paraná - SESA/PR (Paraná, 1999).

Adicionalmente, englobou-se também representantes da indústria alimentícia - ramo de atividade: beneficiamento de chá, mate e outras ervas para infusão, localizadas em Curitiba, e exportadoras citadas pela Companhia de Processamentos de Dados do Estado do Paraná (Paraná, 2001) e/ou identificadas a partir de visualização de seu produto sob forma de chá de capim-limão comercializado em supermercados curitibanos.

Paralelamente, entrevistou-se representantes do setor de comercialização de produtos naturais, incluindo as farmácias de manipulação, as homeopáticas e o Mercado Público Municipal de Curitiba. De forma complementar, procedeu-se a entrevistas com técnicos responsáveis pelo setor de mercearia seca dos principais supermercados de Curitiba, de acordo com o faturamento e posicionamento no ranking das empresas brasileiras supermercadistas, segundo a Associação Brasileira de Supermercados - ABRAS (2000). Nesta etapa, visou-se confirmar dados obtidos nas fases anteriores, além de caracterizar este segmento da cadeia.

Adicionalmente, realizaram-se várias análises laboratoriais (qualidade microbiológica e/ ou físico-química de solos, da planta, óleo essencial, água, marcas de chá, entre outras), de modo a melhor subsidiar a compreensão dos diferentes aspectos relacionados à qualidade da cadeia analisada. 
Efetuou-se cruzamento dos dados obtidos assim como a análise criteriosa destes, referenciada pela legislação brasileira vigente dos Ministérios da Agricultura e Saúde (Agência Nacional de Vigilância Sanitária) relacionada aos aspectos fitossanitários e ao controle sanitário de alimentos, incluindo as condições higiênico-sanitárias e de boas práticas de elaboração para estabelecimentos elaboradores/ industrializadores de alimentos, inspeção sanitária de alimentos, Boas Práticas de Produção e de Prestação de Serviços na Área de Alimentos, Padrão de Identidade e Qualidade - (PIQs) para Serviços e Produtos na área de Alimentos, Sistema de Análise de Perigos e Pontos Críticos de Controle, acondicionamento, rotulagem de alimentos embalados, padrões microbiológicos em alimentos. Também foram consideradas as recomendações da Sociedade Brasileira de Ciência e Tecnologia de Alimentos - SBCTA e da Associação Brasileira de Profissionais da Qualidade de Alimentos-PROFIQUA/SBCTA sobre Boas Práticas de Transporte e Armazenagem de Alimentos e Boas Práticas de Fabricação para empresas de alimentos. Além disso, também foram consultadas as recomendações das instituições internacionais da área como a American Public Health Association - APHA e a Food and Drug Administration, dentre outras. E, para complementar, consideraram-se as recomendações da Farmacopéia Brasileira.

\section{RESULTADOS E DISCUSSÃO}

No total, foram geradas 26 propostas e recomendações para os distintos agentes da cadeia produtiva do capim-limão do Estado do Paraná, categorizadas de acordo aos distintos problemas identificados, com ênfase no cultivo e processamento, dado que estas atividades foram evidenciadas como mais problemáticas e limitadoras da oferta de um produto adequado para comércio e consumo (Tab.1).

Alguns esclarecimentos sobre a pertinência destas propostas e recomendações são apresentados a seguir:

\section{Quanto ao nome específico do produto (itens 1 e 2 - Tabela 1) \\ O nome específico que caracteriza um} alimento, como o chá de capim-limão, é fixado por regulamento técnico, no caso dos chás pela Portaria 277/05 (Brasil, 2005), que define os "Padrões de Identidade e Qualidade". Este nome específico é chamado "denominação de venda do alimento" pela RDC 259/02 (Brasil, 2002). Esta informação é obrigatória e deve constar do painel principal do produto.
Porém, conforme Gomes et al. (2005), no caso do capim-limão, a própria Portaria $n^{\circ}$. 519/98 do Ministério da Saúde Secretaria de Vigilância em Saúde que estabelece o regulamento técnico para fixação de identidade e qualidade de chás - plantas destinadas à preparação de infusões ou decocções, apresenta incorreção na grafia do nome cientifico. Ao invés de Cymbopogon citratus (D.C.) Stapf, apresenta como nome científico Cymbopogon citratus Stapf, o que se configura numa incorreção na autoria desta espécie.

Também há que se considerar, na análise da grafia, os aspectos da nomenclatura botânica que estabelecem que nomes científicos, por estarem em latim, devem estar em negrito ou itálico, sendo apenas a inicial do nome do gênero em letra maiúscula. Todo nome científico deve estar acompanhado do nome correto do autor da espécie, assim como deve refletir a história de alterações deste nome a partir de sua proposição.

Todas as marcas analisadas, num total de 19, indicavam em seu rótulo a espécie vegetal Cymbopogon citratus como matéria prima de seu produto. Entretanto, em 9 marcas detectou-se incorreções ou omissões parciais na grafia do nome científico desta espécie. Nestes casos, indica-se a adequação destas grafias de modo a minimizar quaisquer possibilidades de erro de identificação do material comercializado.

Estas diferentes marcas, também, apresentavam variação na indicação do nome popular da espécie em questão, sendo "capimcidreira" o mais utilizado $(47,4 \%$ das marcas) seguida por "capim-limão" (26,3\%). Em 10\% das marcas, registrou-se a denominação "erva-cidreira", também empregada para outras espécies botânicas como Lippia alba (Mill.) N.E.Br. ex Britt \& Wilson e Melissa officinalis L.

Para resolver esta questão, seria necessário em primeira instância que órgãos normativos como a ANVISA adotassem a grafia do nome científico e não permitissem apenas o uso do nome popular na comercialização de espécies medicinais, incluindo o capim limão. Adicionalmente, os setores primário, secundário e terciário devem estar pautados na identificação botânica correta do capim-limão, promovendo sua comercialização pelo adequado nome científico: Cymbopogon citratus (DC.) Stapf.

\footnotetext{
Oferta e demanda do produto agrícola (itens 3 e 4 - Tabela 1)

Conforme evidenciado por Gomes (2001), cerca de $80 \%$ dos produtores agroindustriais, não seguem o calendário agrícola adequado à cultura do capim-limão. O cultivo desta espécie é pouco planejado e está inserido de forma pouco expressiva no contexto de outras culturas nas
} 
TABELA 1. Recomendações e propostas para os agentes da cadeia produtiva do capim-limão do Estado do Paraná.

\begin{tabular}{|c|c|c|c|c|c|c|c|c|c|}
\hline Recomendações e propostas & sP & SS & ST & $\mathrm{CO}$ & PE & ANVISA & SEAB/PR & EMA-TER & IAPAR \\
\hline $\begin{array}{l}\text { 1- Proceder à identificação botânica correta do } \\
\text { capim-limão, desde o nível de produção, e somente } \\
\text { ser comercializado pelo nome científico correto da } \\
\text { espécie: Cymbopogon citratus (DC.) Stapf }\end{array}$ & $x$ & $x$ & $x$ & & & & & & \\
\hline $\begin{array}{l}\text { 2- Acrescentar na Portaria } 277 / 05^{*} \text { a obrigatoriedade } \\
\text { da adoção do nome específico científico correto do } \\
\left.\text { capim-limão. * (revogou a Portaria } n^{\circ} 519 / 98\right)\end{array}$ & & & & & & $x$ & & & \\
\hline $\begin{array}{l}\text { 3- Estabelecer calendário agrícola adequado à } \\
\text { cultura do capim-limão conforme demanda regional }\end{array}$ & $x$ & $x$ & $x$ & & $x$ & & & $x$ & $x$ \\
\hline $\begin{array}{l}\text { 4- Formalizar contrato entre as partes envolvidas } \\
\text { na comercialização, de modo a evitar situações que } \\
\text { possam gerar prejuízos. }\end{array}$ & $x$ & $x$ & $x$ & & & & & & \\
\hline $\begin{array}{l}\text { 5- Adotar práticas agroecológicas e corretas de } \\
\text { manejo sob orientação técnica, incluindo o uso de } \\
\text { adubo orgânico bem curtido. }\end{array}$ & $x$ & & & & & & & & \\
\hline $\begin{array}{l}\text { 6- Utilizar mudas de boa qualidade, adquirida de } \\
\text { órgãos públicos ou empresas privadas certificadas. } \\
\text { Não utilizar mudas procedentes de ações extrativistas } \\
\text { como, por exemplo: colheita à beira de estradas. }\end{array}$ & $x$ & & & & & & & & \\
\hline $\begin{array}{l}\text { 7- Na colheita, empregar ferramentas afiadas e } \\
\text { higienizadas com solução comercial de hipoclorito } \\
\text { de sódio } 5 \% \text {. Os coletores devem obrigatoriamente } \\
\text { usar luvas adequadas à textura do material vegetal, } \\
\text { touca e roupas apropriadas para a colheita e para o } \\
\text { trabalho na unidade de beneficiamento. }\end{array}$ & $x$ & $x$ & & & & & & & \\
\hline $\begin{array}{l}\text { 8- Até que seja estabelecido procedimento mais } \\
\text { adequado, realizar a colheita no período na manhã, } \\
\text { evitando a colheita no inverno, quando a área foliar } \\
\text { estiver danificada pelo frio. }\end{array}$ & $x$ & & & & & & & & \\
\hline $\begin{array}{l}\text { 9- Estabelecer procedimento de plantio, tratos } \\
\text { culturais, colheita e beneficiamentos adequados às } \\
\text { condições ambientais do Estado do Paraná. }\end{array}$ & & & & & $x$ & & $x$ & $x$ & $x$ \\
\hline $\begin{array}{l}\text { 10- Realizar secagem logo após a colheita e } \\
\text { acondicionar a erva em recipientes adequados às } \\
\text { condições de armazenamento. }\end{array}$ & $x$ & $x$ & & & & & & & \\
\hline $\begin{array}{l}\text { 11- Na secagem, preferir o uso de secadores com } \\
\text { circulação de ar quente e cuidar para manter a } \\
\text { temperatura nos limites estabelecidos para o capim- } \\
\text { limão. }\end{array}$ & $x$ & $x$ & & & & & & & \\
\hline $\begin{array}{l}\text { 12- Exigir produto de qualidade, ou seja, que atenda } \\
\text { a legislação brasileira. }\end{array}$ & & $x$ & $x$ & $x$ & & & $x$ & & \\
\hline $\begin{array}{l}\text { 13- Exigir laudo técnico, especificando dados como } \\
\text { a data e hora da colheita, temperatura de secagem } \\
\text { e as análises de qualidade realizadas. }\end{array}$ & & $x$ & $x$ & & & & $x$ & $x$ & \\
\hline $\begin{array}{l}\text { 14- Exigir laudo técnico de plantas que sofreram } \\
\text { processo de irradiação, explicando o processo } \\
\text { utilizado. }\end{array}$ & & $x$ & $x$ & $x$ & & $x$ & $x$ & & \\
\hline $\begin{array}{l}\text { 15- Promover continuamente a transferência } \\
\text { de informações técnico-científicas e legislação } \\
\text { brasileira vigente sobre boas práticas agrícolas, } \\
\text { de armazenagem, transporte e fabricação através } \\
\text { de cursos, distribuição de cartilhas e de manual de } \\
\text { boas práticas, com linguagem acessível aos diversos } \\
\text { agentes da cadeia produtiva. }\end{array}$ & & $x$ & & & & $x$ & $x$ & $x$ & $x$ \\
\hline
\end{tabular}


TABELA 1. Recomendações e propostas para os agentes da cadeia produtiva do capim-limão do Estado do Paraná.

continuação...

16- O tempo de armazenamento do produto bruto

(folhas verdes ou desidratadas) e final (chá/óleo

essencial) deve ser o menor possível, no máximo

um ano, para garantir a qualidade em termos

qualitativos e quantitativos.

17- Implantar sistema de controle e monitoramento de temperatura e umidade adequadas ao produto comercializado nas áreas de armazenagem (chá/ óleo).

18- Na colheita, transporte e armazenamento, $\mathrm{x} \quad \mathrm{x}$

utilizar caixas plásticas ou lonas plásticas íntegras, previamente higienizadas.

19- Priorizar o uso de embalagens secundárias ou terciárias, pela maior proteção que oferecem ao alimento.

20- Estabelecer Sistema de Análise de Perigos e Pontos Críticos de Controle em associação à formulação e contínua aplicação de normas de Boas Práticas de Fabricação, Armazenagem e Transporte, visando implantação das normas da série ISO-9000.

21- Conhecer e aplicar as normas do Ministério da Saúde - ANVISA e do Ministério da Agricultura, Pecuária e Abastecimento.

22- Realizar análises de controle de qualidade no produto de acordo com a legislação nacional vigente pelo Ministério da Saúde-ANVISA. Proceder reanálises de produto armazenado, que se destinará a comercialização.

23- Inserir na RDC n 12/01 (Brasil, 2001a) - chás, a obrigatoriedade das pesquisas microbiológicas relativas à Escherichia coli e coliformes fecais (Termotolerantes) e também bolores e leveduras, pois representam mecanismo adicional eficiente na prevenção de doenças transmitidas por alimentos. 24- Inserir a rotulagem nutricional, em forma de tabela, incluindo: o valor calórico, seguido da

$\mathrm{X} \times \mathrm{x}$

$\mathrm{X}$

$x \quad x$

$\mathrm{x} x$

$x \quad x$

$x \quad x$

$x \quad x \quad x$

$x \quad x$
declaração de nutrientes e componentes básicos, na seguinte ordem: carboidratos, proteínas, gorduras totais e sódio, conforme determina a legislação-RDC n³60/03 (Brasil, 2003) (revogou RDC 39/01 e 40/01).

25- Promover maior divulgação do conhecimento científico a respeito dos constituintes químicos, atividades biológicas, aspectos botânicos e ecológicos do capim-limão de forma a fortalecer a aplicação industrial desta planta.

26- Estabelecer núcleos centralizadores de informações e de capacitação nos diferentes núcleos regionais de produção.

Nota: SP, SS, ST= setor primário, secundário e terciário, respectivamente; CO= consumidor; PE=pesquisa.

Rev. Bras. Pl. Med., Campinas, v.17, n.2, p.201-209, 2015. 
propriedades agrícolas. Assim, é preciso que haja um esforço integrado entre diferentes atores da cadeia produtiva e instituições intervenientes para estabelecer o calendário agrícola desta cultura, com vistas à produção programada e oferta escalonada, conforme demanda regional por sistemas de parcerias. O calendário agrícola é o principal elo faltante na cadeia produtiva do capim-limão (Gomes et al., 2004). Desta forma, sua implantação evitaria prejuízos ao agricultor.

Adicionalmente, para não por em risco a atividade profissional dos setores primário, secundário e terciário envolvidos, é essencial que seja formalizado contrato entre as partes para a comercialização, de modo a evitar situações que também possam gerar prejuízos a estes.

\section{Tabela 1)}

Cultivo e beneficiamento (itens 5 a 15 -

$\mathrm{Na}$ pesquisa que visou caracterizar os procedimentos associados à produção desta espécie no Estado do Paraná, os principais problemas evidenciados relacionavam-se ao desconhecimento por parte dos produtores quanto a vários aspectos desta cultura, incluindo desde a obtenção adequada de mudas, época adequada de plantio e de colheita para maximização de biomassa e do teor de princípios ativos assim como o controle adequado de pragas e doenças (Gomes et al., 2007b). A condução da lavoura de capim-limão estava delimitada ao uso de técnica experimental de erro e acerto, privilegiando o menor custo de investimento em capital humano e financeiro. A eficiência e a eficácia da tecnologia aplicada deixavam a desejar quanto à qualidade do produto, do processo produtivo e dos serviços capim-limão. A contaminação microbiológica foi identificada como o principal gargalo higiênico-sanitário, com origem na inadequação tecnológica da época de colheita e permeando o manuseio do produto, vestimenta inadequada dos manipuladores, do local e dos equipamentos de secagem assim como no armazenamento, embalagem e, transporte deste produto. Estes fatores em conjunto condicionavam o baixo rendimento industrial do capim-limão, quando processado em óleo essencial (Gomes et al.,2004).

Desta forma identifica-se, como imprescindível e urgente, a transferência de informações técnicas aos produtores, incluindo aquelas relativas à aplicação de boas práticas agrícolas na cultura do capim-limão de modo a garantir a melhor qualidade do produto a ser comercializado.

O setor secundário e terciário e o consumidor devem exigir do setor primário um produto de qualidade, com devido laudo técnico, incluindo dados da colheita, secagem e as análises de qualidade realizadas. Adicionalmente, este laudo também deve registrar se o produto foi submetido a processo de irradiação, conforme regulamentado para alimentos pela RDC № 21 de 26 de janeiro de 2001 (Brasil, 2001b). Esta informação deve também constar no rótulo do produto comercializado. Salienta-se que o uso de irradiação é permitido e quando bem conduzido é um dos processos de descontaminação microbiana muito eficaz na diminuição da carga microbiana, conforme salientam Satomi et al. (2005).

\section{Armazenamento e transporte (itens 15 a 19 - Tabela 1) \\ O armazenamento inadequado, pode gerar} perda de princípios ativos do produto e favorecer a contaminação por agentes diversos que, por sua vez podem causar danos à saúde do consumidor, além de determinar prejuízos econômicos ao empresário envolvido. O armazenamento é, portanto, um elemento de importância crítica em qualquer sistema de comercialização.

Em avaliação do setor terciário, evidenciouse que o problema mais frequentemente registrado na comercialização do capim-limão, tanto nas lojas quanto nos depósitos, era a falta de controle de temperatura e umidade adequadas (ausentes na totalidade dos estabelecimentos visitados). Um outro problema, que igualmente foi registrado com relativa frequência, era o não atendimento do espaçamento mínimo requerido. Com menor frequência, foram evidenciadas inadequações quanto à limpeza do local de armazenagem e luminárias, proximidade de produtos tóxicos além da forma e qualidade do empilhamento (Gomes et al., 2007c).

\section{Análises de controle de qualidade (itens 20 a 24 - Tabela 1). \\ Em avaliação da cadeia de comercialização} do capim-limão, identificou-se questões relativas à qualidade microbiológica e físico-química do conteúdo do sachê, cuja responsabilidade está atrelada aos diferentes segmentos da cadeia produtiva. As práticas incorretas do setor primário, a falta de controle de qualidade do setor secundário e as inadequações de armazenagem do setor terciário, isoladamente ou sinergeticamente associadas, eram determinantes da má qualidade observada em algumas marcas comercializadas (Gomes et al., 2004; 2007c).

Devido ao crescimento no consumo de plantas medicinais, em diversas formas de uso, o compromisso das agências reguladoras também aumenta. Estas deve assegurar a qualidade do produto, visando à segurança do consumidor e todos agentes envolvidos na cadeia produtiva, zelando pelo cumprimento das normas oficiais. 
Por sua vez, desde a produção ao setor de industrialização, os agentes econômicos envolvidos devem buscar conhecer e aplicar as normas do Ministério da Saúde - ANVISA e do Ministério da Agricultura, Pecuária e Abastecimento. Assim, devem realizar análises de controle de qualidade no produto de acordo com a legislação nacional vigente. Também, é recomendável proceder reanálises de produto armazenado, que se destinará a comercialização.

Cabe ainda aos setores primário ao terciário, além de cumprirem com as normas dos dois Ministérios, procurarem utilizar o Sistema de Análise de Perigos e Pontos Críticos de Controle, proposto por Bryan (1992), empregado no Brasil, como referência no controle sanitário de alimentos (vide Portaria no 1.428- ANVISA - (Brasil, 1993), em associação à formulação e contínua aplicação de normas de Boas Práticas de Fabricação, Armazenagem e transporte, visando à implantação das normas da série ISO-9000, subsidiados por órgãos Públicos como a SEAB e EMATER

Entretanto, a legislação quanto às análises de qualidade microbiológica de chás, (ANVISA- RDC 12/01, Brasil, 2001a) apresenta uma importante lacuna. Esta não inclui a obrigatoriedade das pesquisas microbiológicas relativas à Escherichia coli e coliformes fecais (termotolerantes) assim como pesquisa de bolores e leveduras, no sentido de garantir maior qualidade ao produto e segurança alimentar ao consumidor. Estes organismos têm sido frequentemente identificados de forma expressiva em amostras de chá, incluindo capim-limão (Gomes, 2008) e outros (Bugno et al., 2005; Rocha et al., 2004).

Outra lacuna importante refere-se a falta de estabelecimento dos teores aceitáveis de metais pesados, conforme salientado por Vulcano et al. (2008).

Formação técnica, capacitação e transferência de tecnologia (itens 25-26 - Tabela).

A cadeia produtiva do capim-limão no Estado do Paraná apresenta gargalos importantes atrelados fortemente à falta de orientação técnica e capacitação dos diferentes agentes envolvidos. Desta forma, ações neste sentido são necessárias para qualificar a cadeia produtiva do capim-limão e devem ser promovidas integrando estes diferentes agentes com apoio de pesquisadores e órgãos públicos como a ANVISA, SEAB, EMATER E IAPAR.

Estas ações devem ser contínuas, em linguagem e material adequados aos distintos agentes, incluindo informações técnico-científicas assim como repasse da legislação brasileira vigente sobre boas práticas agrícolas, de armazenagem, transporte e fabricação. Para facilitar este processo, cabe especialmente a SEAB e a EMATER a criação de núcleos centralizadores de informações e de capacitação nos diferentes núcleos regionais de produção.

\section{CONSIDERAÇÕES FINAIS}

A eficiência e competitividade de uma cadeia produtiva resultam de um esforço integrado entre todos os agentes que nela participam ou intervém. Quando esta integração é adequada, observa-se que os sistemas produtivos atrelados a esta cadeia conseguem sustentar ou ampliar, duradouramente, suas posições competitivas no mercado. É a capacidade sustentável de sobreviver e, de preferência, crescer nos mercados concorrentes ou em novos mercados.

O ambiente competitivo enfrentado hoje pelas pequenas unidades produtivas coloca como padrão gerencial e operacional, atenção no mercado consumidor, onde a oferta de seus produtos deve se ajustar aos desejos e expectativas deste mercado, que agrega o conceito de qualidade e adequação tecnológica aos processos e produtos, como a observação dos padrões da embalagem e apresentação geral do produto pertinente ao tamanho, forma, cor e aroma. A racionalização do sistema vai além do processo produtivo, pois mantém ainda uma estreita relação com outros aspectos operacionais ligados a comercialização da produção, chegando até o consumidor.

Nesta perspectiva, espera-se que as propostas e recomendações aqui apresentadas possam contribuir para a melhor estruturação e integração da cadeia produtiva do capim-limão no Estado do Paraná, ou mesmo de outros Estados com características similares.

Reitera-se que são imprescindíveis ações integradas de orientação técnica e capacitação dos diferentes agentes envolvidos, com apoio de pesquisadores e órgãos públicos como a ANVISA, SEAB, EMATER E IAPAR.

Adicionalmente, reforça-se a responsabilidade dos órgãos de fiscalização competentes e dos consumidores de chá e produtos derivados de capim-limão, no sentido de exigir qualidade e segurança alimentar.

\section{AGRADECIMENTO}

Aos agentes econômicos que integram a cadeia produtiva do capim-limão no Estado do Paraná, aos funcionários da Secretaria Estadual e Secretarias Municipais da Saúde e da Agricultura, Pecuária e Abastecimento do Paraná, bem como à chefia e servidores do Laboratório Central de Saúde Pública do Paraná e a funcionários do Setor de 
Microbiologia do TECPAR/PR, pelos diversos tipos de auxílio e gentileza nos esclarecimentos prestados durante a coleta e análise de dados.

\section{REFERÊNCIAS}

ABRAS. ASSOCIAÇÃO PARANAENSE DE SUPERMERCADOS. Ranking Abras. Edição

2000. Superhiper, São Paulo, v. 26, p. 26-29, 70, 82-94, 123. 2000.

ADEBAYO, T.A.; GBOLADE, A.A. Protection of stored cowpea from Callosbruchus maculatus using plant products. Insect Science and its Application, v.15, p.185-9, 1994.

BALBOA, J.G.; LIM, C.Y.S. Effect of some medicinal plants on skin tumor promotion. Phillipine Journal of Science, v.124, n.2, p.203-7, 1995.

BRASIL. Ministério da Saúde. Secretaria de Vigilância Sanitária. Portaria da SVS n. 1.428 de 26 de novembro de 1993. Regulamento técnico para inspeção sanitária de alimentos. Diário Oficial da União, Brasília, Poder Executivo, de 02 dez. 1993.

BRASIL. Ministério da Saúde. Agência Nacional de Vigilância Sanitária. Resolução da Diretoria Colegiada RDC n.12, de 02 jan. 2001. "Regulamento técnico sobre os Padrões Microbiológicos para alimentos". Diário Oficial da União, Brasília, 10 jan. 2001 a.

BRASIL. Ministério da Saúde. Agência Nacional de Vigilância Sanitária. Resolução de Diretoria Colegiada - RDC n.21, de 26 de janeiro de 2001. "Regulamento técnico para irradiação de alimentos”. Diário Oficial da União, Brasília, DF, 29 jan. 2001b.

BRASIL. Ministério da Saúde. Agência Nacional de Vigilância Sanitária. Resolução de Diretoria Colegiada RDC n.259, de 20 de setembro de 2002. "Regulamento técnico para rotulagem de alimentos embalados". Diário Oficial da União, Brasília, DF, 23 set. 2002.

BRASIL. Resolução de Diretoria Colegiada - RDC n. 360, de 23 de dezembro de 2003. A Agência Nacional de Vigilância Sanitária aprova o "Regulamento Técnico sobre Rotulagem Nutricional de Alimentos Embalados, tornando obrigatória a rotulagem nutricional”. Diário Oficial da União, Poder Executivo, de 26 de dezembro de 2003. Disponível em: <http://e-legis.anvisa.gov.br/ leisref/public >. Acesso em: 24 ago. 2009.

BRASIL. Resolução de Diretoria Colegiada - RDC n. 277, de 22 de setembro de 2005. A Agência Nacional de Vigilância Nacional aprova o "Regulamento Técnico para café, cevada, chá, erva-mate e produtos solúveis". Anexo: Regulamento Técnico para café, cevada, chá, mate e produtos solúveis. 2005. Diário Oficial da União, Poder Executivo, de 23 de setembro de 2005. Disponível em: <http://e-egis.anvisa.gov.br/leisref/ public>. Acesso em: 24 ago. 2009.

BRYAN, F. Análise de perigos e pontos críticos de controle. Genebra: OMS, 1992.

BUGNO, A. et al. Avaliação da contaminação microbiana em drogas vegetais. Revista Brasileira de Ciências Farmacêuticas, v.41, n.4, p.491-7, 2005.

CHALCHAT, J.C.O. et al. Correlation between chemical composition and antimicrobial activity. VI. Activity of some African essential oils. Journal of Essential Oil Research, v.9, n.1, p.67-75, 1997.

DUBEY, N.K.; TAKEDA, K.; ITOKAWA, H. Citral: a cytotoxic principle isolated from the essential oil of Cymbopogon citratus against $P 388$ leukemia cells. Currente Science, v. 73, p.22-4, 1997.

GILBERT, B. et al. Activities of the pharmaceutical technology institute of oswaldo cruz foundation with medicinal, insecticidal and insect repellent plants. Anais da Academia Brasileira de Ciências, v.71, n.2, p.265-71, 1999.

GOMES, E.C. Aspectos do cultivo e beneficiamento do capim limão ("Cymbopogon citratus" (DC.) Stapf) no Estado do Paraná, Brasil. Visão Acadêmica, v.2, n.1, p.11-8, 2001.

GOMES, E.C. Subsídios para melhoria de qualidade do cultivo, industrialização e comercialização do Capim-limão Cymbopogon citratus (DC.) Stapf no Estado do Paraná. 2003. 184p. Tese (Doutorado em Agronomia - Área de Concentração em Produção Vegetal) - Departamento de Fitotecnia e Fitossanitarismo. Setor de Ciências Agrárias, Universidade Federal do Paraná, Curitiba.

GOMES, E.C.; RÜCKER, N.G.A.; NEGRELLE, R.R.B. Estudo prospectivo da cadeia produtiva do capim-limão Estado do Paraná. Revista de Economia e Sociologia Rural v.42, p.709-31, 2004.

GOMES, E.C.; NEGRELLE, R.R.B.; RÜCKER, N.G.A. Acondicionamento e rotulagem do chá de capim-limão (Cymbopogon citratus (DC.) Stapf) comercializado pelo segmento supermercado na cidade de Curitiba. Visão acadêmica, v.6, p.61-76, 2005.

GOMES, E.C.; NEGRELLE, R.R.B. CAPIM-LIMÃO - Cymbopogon citratus (D.C.) Stapf: Subsidy to improvment of quality in the crop, industrialization and marketing in paraná state. Scientia Agrária, v.7, n.1, p.119-20, 2006.

GOMES, E.C.; NEGRELLE, R.R.B.; BIASI, L.A. Diagnóstico dos procedimentos de colheita e póscolheita do capim-limão (Cymbopogon citratus (DC.) Stapf) no Estado do Paraná, Brasil. Revista Brasileira de Plantas Medicinais, v.9, p.70-5, 2007a.

GOMES, E.C.; NEGRELLE, R.R.B.; DONI FILHO, L. Capim-limão: caracterização geral do cultivo no Estado do Paraná, Brasil. Scientia Agrária, v.8, p.385-90, 2007b.

GOMES, E.C.; ELPO, E.R.S.; NEGRELLE, R.R.B. Armazenamento de chás no setor supermercadista. Ciência e Tecnologia de Alimentos, v.27, p.675-80, 2007c.

GOMES, E.C.; NEGRELLE, R.R.B.; ELPO, E.R.S. Determinação da qualidade microbiológica e físicoquímica de chás de Cymbopogon citratus (DC.) Stapf (capim-Limão). Acta Scientiarium Health Scientiarum, v.30, n.1, p.47-54, 2008.

LORENZETTI, B.B. et al. Myrcene mimics the peripheral analgesic activity of lemon grass tea. Journal of Ethnopharmacology, v.34, p.43-8, 1991.

MARTINS, E.R.; MELO, E.C. Avaliação da altura da camada no processo de secagem de folhas de Cymbopogon citratus (STAPF.) DC. Disponível em: < http//www.ufv.br>. Acesso em: 20 ago. 2002.

ONAWUNMI, G.O.; YISAK, W.A.; OGUNLANA, G.O. 
Antibacterial constituents in the essential oil of Cymbopogon citratus (DC.) Stapf. Journal of Ethnopharmacology, v.12, p. 279-86, 1984.

ONAWUNMI, G.O. In vitro studies of the antibacterial activity of phenoxyethanol in combination with lemon grass oil. Die Pharmazie Eschborng, v.43, p.42-4, 1988.

PARANÁ. Secretaria de Estado da Saúde. Departamento de Vigilância Sanitária.Relação das indústrias aprovadas pelo PNIF. Curitiba, 1999.

PARANÁ. Companhia de Processamento de Dados do Estado do Paraná. Dados cadastrais de empresas de beneficiamento de chá, mate e outras ervas para infusão/ beneficiamento, moagem e preparação de outros alimentos de origem vegetal. Disponível em: <http://www.celepar7. pr.gov.br/produserv/consulta>. Acesso em: ago. 2001.

PARANÁ. Secretaria de Estado da Agricultura e do Abastecimento. Departamento de Economia Rural.
Valor Bruto da Produção Agropecuária Paranaense em 2006. Curitiba: SEAB/PR. 2008.

RANKEN, M.D. Manual de industrias de los alimentos. 2.ed. Zaragoza: Acribia, 1993. 672p.

ROCHA, L.O.; SOARES, M.M.S.R.; CORREA, C.L. Análise da contaminação fúngica em amostras de Cássia acutifólia Delile (sene) e Peumus boldus (Molina) Lyons (boldo-do-Chile) comercializados na cidade de Campinas, Brasil. Revista Brasileira de Ciências Farmacêuticas, v.40, n.4, p.521-7, 2004.

SATOMI, L.C.; SORIANI, R.R.; PINTO, T.J.A. Descontaminação de drogas vegetais empregando irradiação gama e óxido de etileno: aspectos microbianos e químicos. Revista Brasileira de Ciências Farmacêuticas, v.41, n.4, p.445-50, 2005.

VULCANO, I.R.C.; SILVEIRA, J.N.; LEITE, E.M.A. Teores de chumbo e cádmio em chás comercializados na região metropolitana de Belo Horizonte. Revista Brasileira de Ciências Farmacêuticas, v.44, n.3, p.425-31, 2008. 